\title{
PENATALAKSANAAN FISIOTERAPI PADA GANGGUAN NYERI AKIBAT CARPAL TUNNEL SYNDROME DENGAN MODALITAS ULTRASOUND DAN CARPAL BONE MOBILIZATION DI RUMAH SAKIT BHAYANGKARA TK. III BANJARMASIN
}

(Management of Physiotherapy in pain disorders due to Carpal Tunnel Syndrome with Ultrasound Modality and Carpal Bone Mobilization in Bhayangkara TK. III Hospital Banjarmasin)

\author{
Nila Nur Azizah, Maulida Wijaya Putri ${ }^{1}$, Arfian Hamzah ${ }^{1}$ \\ ${ }^{1}$ Program Studi D-III Fisioterapi Politeknik Unggulan Kalimantan \\ Email: nilanurazizah98@gmail.com
}

\begin{abstract}
Carpal tunnel syndrome (CTS) is one of the upper extremity disorders caused by narrowing of the carpal tunnel resulting in an emphasis on the median nerve located on the wrist. The disorder that occurs in this case is pain, this study aims to determine the effects of Ultrasound and carpal bone mobilization in reducing pain in cases of carpal tunnel syndrome. This research method uses a case study that discusses one case in depth. This study was measured using a Visual Analogue Scale (VAS) to determine the decrease in pain before and after therapy. The results of this study found that there was a decrease in pain after therapy.
\end{abstract}

Keywords : Carpal Tunnel Syndrome (CTS), Visual Analogue Scale (VAS), Ultrasound, and Carpal Bone Mobilization.

\begin{abstract}
ABSTRAK
Carpal tunnel syndrome (CTS) merupakan salah satu gangguan ekstremitas atas yang disebabkan oleh penyempitan pada terowongan karpal sehingga terjadi penekanan terhadap nervus medianus yang terletak pada pergelangan tangan. Gangguan yang terjadi pada kasus ini adalah nyeri, penelitian ini bertujuan untuk mengetahui efek dari Ultrasound dan carpal bone mobilization dalam menurunkan nyeri pada kasus carpal tunnel syndrome. Metode penelitian ini menggunakan case study yang membahas satu kasus secara mendalam. Penelitian ini diukur dengan menggunakan Visual Analogue Scale (VAS) untuk mengetahui penurunan nyeri saat sebelum dan sesudah dilakukan terapi. Hasil dari penelitian ini didapatkan bahwa terdapat penurunan nyeri setelah dilakukan terapi..
\end{abstract}

Kata kunci : Carpal Tunnel Syndrome (CTS), Visual Analogue Scale (VAS), Ultrasound, dan Carpal Bone Mobilization 


\section{PENDAHULUAN}

Tangan merupakan salah satu anggota gerak tubuh yang paling sering digunakan dalam berbagai aktivitas sehari-hari. Aktivitas tangan dan pergelangan tangan yang berlebihan jika berlangsung lama dapat menimbulkan suatu masalah dan menyebabkan risiko penyakit akibat kerja. Salah satu masalah yang sering terjadi pada tangan yaitu carpal tunnel syndrome (CTS) (Tarwaka, 2008).

Carpal tunnel syndrome merupakan salah satu gangguan ekstremitas atas yang disebabkan oleh penyempitan pada terowongan carpal sehingga terjadi penekanan terhadap syaraf medianus yang terletak di pergelangan tangan (Woodall, 2010). Sebagian kasus carpal tunnel syndrome tidak diketahui secara jelas penyebabnya, namun sangat erat hubungannya dengan penggunaan tangan secara berulang dan berlebihan (Morina et al., 2012). Tanda dan gejala CTS mepiluti rasa nyeri, kesemutan atau kebas pada bagian distal (jempol, telunjuk, jari tengah dan sisi radial jari manis), kemampuan menggenggam berkurang dan mempengaruhi gerak fungsional (Ibrahim et al., 2012).

Carpal tunnel syndrome merupakan masalah umum dengan angka kejadian setiap tahunnya adalah 0,5-5,1 per 1000 dan di Inggris antara tahun $1992-2001$ terdapat 6.245 pasien $(55,5 \%)$ menderita CTS (Jagga et al., 2011). Menurut Newington et al (2015), carpal tunnel syndrome lebih sering terjadi pada wanita dengan kejadian tahunan 1,5 per 1000 dan 0,5 per 1000 pada pria. Insidensi pada wanita puncaknya terjadi pada usia 45 tahun. Di Indonesia prevalensi CTS antara 5,6\% sampai 15\%. Di Banjarmasin, berdasarkan data pasien rekam medis poli fisioterapi RS. Bhayangkara TK. III pada tahun 2018 terdapat 25 orang yang terdiagnosa CTS.

Berdasarkan penelitian, diketahui bahwa carpal tunnel syndrome dapat ditangani dengan ultrasound. Ultrasound menggunakan arus listrik yang dialirkan melewati transducer yang mengandung kristal kuarsa dan dapat berkontraksi serta memproduksi gelombang suara yang ditransmisikan pada kulit ke dalam tubuh (Arovah, 2010). Ultrsound pada carpal tunnel syndrome bermanfaat untuk mempercepat healing process pada jaringan yang rusak sehingga nyeri akan berkurang (Ono et al., 2010). Selain ultrasound, carpal tunnel syndrome juga dapat ditangani dengan intervensi berupa carpal bone mobilization. Carpal bone mobilization merupakan teknik fisioterapi dengan menggerakkan bagian proksimal dari tulang carpal ke arah dorsal untuk ekstensi wrist atau ke arah palmar untuk fleksi wrist (Ghunay \& Alp, 2015). Tujuan penelitian ini adalah untuk mengetahui penatalaksanaan fisioterapi pada gangguan nyeri akibat carpal tunnel syndrome.

\section{METODE PENELITIAN}

Jenis penelitian ini menggunakan studi kasus (case study) menggunakan satu sampel (satu pasien) yang menderita carpal tunnel syndrome dan diberikan intervensi fisioterapi berupa ultrasound dan carpal bone mobilization dengan frekuensi 2 kali seminggu selama satu bulan. Penelitian dilaksanakan pada tanggal 9 - 30 Mei 2019 di Rumah Sakit Bhayangkara TK.III Banjarmasin.

Data penilitian yang diambil menggunakan data primer dan data sekunder. Data primer diperoleh dari hasil pemeriksaan dan pengukuran langsung pada pasien menggunakan instrumen penelitian yaitu Visual Analogue Scale (VAS), sedangkan data 
Volume 2 No. 1 (April, 2020)

sekunder diperoleh dari medical record atau dari hasil pemeriksaan lainnya seperti CTScan, MRI atau rontgen dari pasien yang menjadi sampel.

Data diolah dengan editing dan tabulating. Data yang terkumpul adalah data hasil pengukuran intensitas nyeri pada carpal tunnel syndrome melalui Visual Analogue Scale (VAS). Setelah diberikan intervensi fisioterapi, data yang diperoleh melalui VAS tadi akan dilihat perkembangannya. Berdasarkan data tersebut dapat dilihat pengaruh pemberian modalitas fisioterapi pada kasus carpal tunnel syndrome dengan gangguan nyeri.

\section{HASIL DAN PEMBAHASAN}

\section{Hasil}

Setelah dilakukan assessment fisioterapi terhadap sampel kasus yaitu pasien atas nama $\mathrm{Ny}$. M usia 45 tahun dengan gangguan nyeri didapatkan problematik fisioterapi adanya nyeri gerak pada pergelangan tangan dan danya nyeri tekan pada area carpal tunnel dextra dan sinistra. Selanjutnya dilakukan pengukuran nyeri sesudah pemberian intervensi menggunakan VAS sehingga didapatkan hasil pengukuran sebagaimana ditunjukan pada gambar 1 .

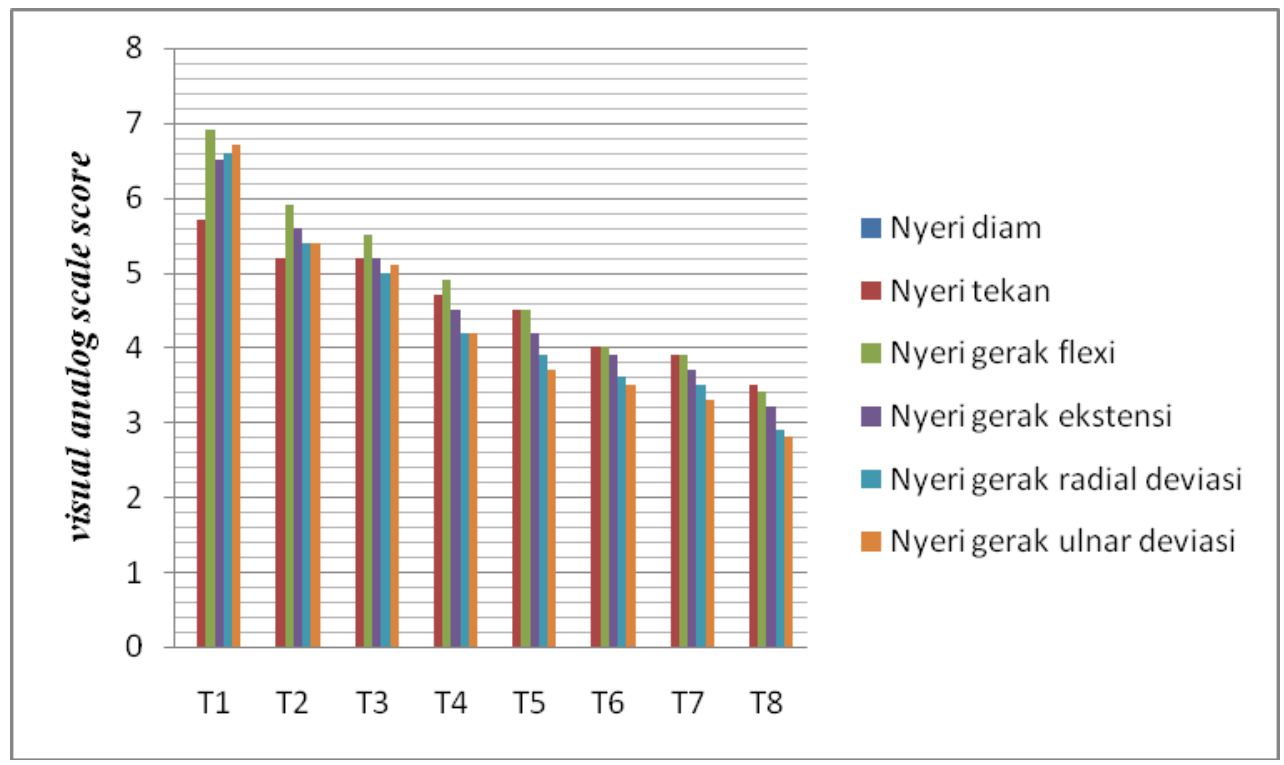

Gambar 1. Hasil pengukuran visual analogue scale (VAS)

Hasil penelitian pada minggu pertama didapatkan hasil pengukuran dengan menggunakan VAS pada terapi pertama yaitu masih sama seperti pada saat sebelum dilakukan terapi.

berbeda - beda bila diukur dengan menggunakan VAS. Terapi ketujuh dengan Pada terapi kedua yang telah dilakukan terdapat penurunan nyeri dengan hasil yaitu nyeri diam $0 \mathrm{~cm}$ (tidak nyeri), nyeri tekan $5,2 \mathrm{~cm}$ (nyeri sedang), nyeri gerak palmar flexi 5,9 $\mathrm{cm}$ (nyeri sedang), nyeri gerak dorsal flexi 5,6 cm (nyeri sedang), nyeri radial deviasi 5,4 $\mathrm{cm}$ (nyeri sedang), nyeri gerak ulnar deviasi $5,4 \mathrm{~cm}$ (nyeri sedang).

Pada minggu keempat terdapat penurunan nyeri, namun penurunan nyeri tersebut memperoleh angka yang hasil nyeri diam $0 \mathrm{~cm}$ (tidakn nyeri), nyeri tekan $3,9 \mathrm{~cm}$ (nyeri ringan), nyeri gerak palmar flexi $3,9 \mathrm{~cm}$ (nyeri ringan), nyeri gerak dorsal flexi $3,7 \mathrm{~cm}$ (nyeri ringan), nyeri gerak radial deviasi $3,5 \mathrm{~cm}$ (nyeri ringan), nyeri gerak ulnar deviasi 
$3,3 \mathrm{~cm}$ (nyeri ringan). Pada terapi terakhir yaitu terapi kedelapan didapatkan hasil nyeri diam $0 \mathrm{~cm}$ (tidak nyeri), nyeri tekan 3,5 (nyeri ringan), nyeri gerak flexi wrist joint 3,4 cm (nyeri ringan), nyeri gerak ekstensi wrist joint 3,2 cm (nyeri ringan), nyeri gerak radial deviasi 2,9 cm (nyeri ringan), nyeri gerak ulnar deviasi 2,8 cm (nyeri ringan).

Hal ini menunjukan bahwa modalitas fisioterapi berupa ultrasound dan carpal bone mobilization efektif dalam menurunkan nyeri, namun intervensi tersebut harus dilakukan secara rutin dan berulang untuk mencapai hasil yang diinginkan.

\section{Pembahasan}

Berdasarkan hasil data di atas, pemberian ultrasound dan carpal bone mobilization yang diberikan selama 8 kali dalam 4 minggu efektif dalam menurunkan nyeri pada pasien Ny. M yang memiliki carpal tunnel syndrome.

Penelitian ini sejalan dengan penelitian yang dilakukan oleh Ono et al (2010) yang menunjukkan bahwa ultrasound dapat mengurangi nyeri pada kasus carpal tunnel syndrome dengan dosis dua kali seminggu. Nyeri dapat berkurang dikarenakan efek thermal yang dihasilkan oleh ultrasound. Efek thermal tersebut mengakibatkan dilatasi pembuluh darah sehingga terjadi peningkatan aliran darah yang membawa oksigen dan nutrisi menjadi lebih lancar sehingga nyeri berkurang (Sugijanto \& Bimantoro, 2008). Menurut Hayes \& Hall (2016), penggunaan ultrasound pada kondisi carpal tunnel syndrome menunjukkan hasil yang lebih baik dibanding terapi dengan modalitas lain. $\mathrm{Hal}$ ini dilihat dari penurunan nyeri secara signifikan setiap minggunya. Menurut Bakhtiary \& Rashidy-Pour (2004), ultrasound lebih efektif dalam mengurangi nyeri sebanding dengan penggunaan splint atau suntikan kortikosteroid.

Sementara itu, penelitian lain oleh Tal-Akabi \& Rushton (2000) menunjukkan bahwa carpal bone mobilization dapat mengurangi nyeri akibat carpal tunnel syndrome dengan dosis dua kali seminggu selama 3 minggu. Menurut Paramita (2017) carpal bone mobilization memiliki dua macam teknik yaitu gerakan traksi dan mobilisasi sendi. Gerakan traksi yang dilakukan pada tulang carpal dan permukaan sendi dapat mengurangi gaya tekan pada sendi. Gaya tekan sendi yang berkurang akan menurunkan tekanan di dalam terowongan carpal sehingga penekanan yang terjadi pada saraf medianus juga akan berkurang. Sedangkan mobilisasi sendi yang berupa fleksi dan ekstensi pada pergelangan tangan dapat memunculkan efek analgesik dan meningkatkan elastisitas struktur sendi. Teknik mobilisasi ini dapat menurunkan nyeri sehingga memungkinkan perluasan gerak dan menambah mobilitas pergelangan tangan. Penelitian tersebut juga sejalan dengan penelitian yang dilakukan oleh Ghunay \& Alp (2015) yang menyebutkan bahwa terdapat penurunan nyeri pada kelompok sampel yang diberikan carpal bone mobilization.

\section{KESIMPULAN}

Penatalaksanaan fisioterapi dengan menggunakan ultrasound dan carpal bone mobilization dapat mengurangi nyeri pada carpal tunnel syndrome.

\section{DAFTAR PUSTAKA}

Arovah, N. I. (2010). Dasar - Dasar Fisioterapi pada Cedera Olahraga. Yogyakarta: FIK UNY.

Bakhtiary, A. H., \& Rashidy-Pour, A. (2004). Ultrasound and Laser Therapy in The Treatment of Carpal Tunnel Syndrome. Aust J Physiother, 50(3), 147-151. 
Ghunay, B., \& Alp, A. (2015). The Effectiveness of Carpal Bone Mobilization Accompanied by Night Splinting in Idiopathic Carpal Tunnel Syndrome. Turk $J$ Phys Med Rehab, 61, 45-50.

Hayes, K., \& Hall, K. (2016). Agen Modalitas untuk Praktik Fisioterapi (6 $6^{\text {th }}$ ed). Jakarta: EGC.

Ibrahim, I., Khan, W. S., Goddard, N., \& Smith, P. (2012). Carpal Tunnel Syndrome: A Review of the Recent Literature. Open Orthop J, 6: 69-76.

Jagga, V., Lehri, A., \& Verma, S. K. (2011). Occupation and Its association with Carpal Tunnel Syndrome - A Review. J Exer Sci Physiother, 7(2): 68-78.

Morina, F., Bytyqil, C., Mustafa, A., \& Morina, G. (2012). Carpal Tunne Syndrome: Diagnosis and Surgical Treatment: Clinic of Orthopedics, University Clinical Center of Kosova, Prishtina, Kosova.

Newington, L., Harris, E. C., \& Walker-Bone, K. (2015). Carpal Tunnel Syndrome and Work. Best Pract Res Clin Rheumatol, 29(3): 440-453.

Ono, S., Clapham, P. J., \& Chung, K. C. (2010). Optimal Management of Carpal Tunnel Syndrome. Int J Gen Med, 3: 255-261.

Paramita, G. P. P. (2017). Efektifitas Kombinasi Carpal Bone Mobilization dengan Nerve and Tendon Gliding terhadap Penurunan Nyeri Akibat Carpal Tunnel Syndrome (CTS) pada Ibu PKK Kecamatan Sukosari Bondowoso. Skripsi. Universitas Muhammadiyah Malang.

Sugijanto \& Bimantoro, A. (2008). Perbedaan Pengaruh Pemberian Ultrasound dan Manual Longitudinal Muscle Stretching dengan Ultrasound dan Auto Stretching terhadap Pengurangan Nyeri pada Kondisi Sindroma Myofacial Otot Upper Trapezius. Jurnal Fisioterapi Indonesia, 8(1): 1-24.

Tal-Akabi, A., \& Rushton, A. (2000). An Investigation to Compare the Effectiveness of Carpal Bone Mobilisation and Neurodynamic Mobilisation as Method of Treatment for Carpal Tunnel Syndrome. Man Ther, 5(4): 214-222.

Tarwaka. (2008). Keselamatan dan Kesehatan Kerja, Manajemen dan Implementasi K3 di Tempat Kerja. Surabaya: Harapan Press.

Woodall, C. (2012). Clinical Guideline for The Conservative Management of Carpal Tunnel Syndrome. Advanced Musculosceletal Physiotherapist: Clinical Guideline Ratification Group. 